Article

\title{
Evaluating the Practice and Outcomes of Applying Regenerative Development to a Large-Scale Project in Victoria, Australia
}

\author{
Dominique Hes $\left.{ }^{(}\right)$, André Stephan * ${ }^{(1)}$ and Sareh Moosavi \\ Faculty of Architecture, Building and Planning, The University of Melbourne, Parkville, VIC 3010, Australia; \\ dhes@unimelb.edu.au (D.H.); sareh.moosavi@unimelb.edu.au (S.M.) \\ * Correspondence: andre.stephan@unimelb.edu.au; Tel.: +61-3-8344-5929
}

Received: 27 November 2017; Accepted: 6 February 2018; Published: 9 February 2018

\begin{abstract}
Regenerative development is one of the critical pathways or processes towards an ecological worldview and a built environment in synergy with the natural environment. This vision aims to restore and support environmental, social and economic flows from a systems perspective. While regenerative development has been discussed in theory and applied to some projects, very few studies have analysed the processes that support its emergence. Our study investigates the design process of an ongoing development project, "Seacombe West" in Victoria, Australia. It evaluates the design outputs, using the LENSES Framework (Living Environments in Natural, Social, and Economic Systems) which is specifically designed to facilitate the emergence of regenerative development thinking. The project included a series of four workshops that led to a set of guidelines that in turn were used to design a masterplan. We evaluate the resulting guidelines, the masterplan, and the experience of the participants through an online survey (70\% response rate) and semi-structured interviews with key stakeholders. Our results show that using LENSES encouraged systems thinking and helps facilitate a transdisciplinary approach towards regenerative development. This evaluation provides insights into how regenerative development can emerge in projects and how the potential for net benefit can be embedded.
\end{abstract}

Keywords: net regenerative regional development; ecological worldview; LENSES Framework; transdisciplinary design

\section{Introduction}

There has been a call from many areas of research and practice for a different approach to sustainable development in the built environment. This has occurred because many of the social and ecological indicators that underpin our civilisation are being eroded. In other words, we are generally failing at our current approach to sustainability. Led by thinkers in the built environment such as Lyle [1], McDonough and Braungart [2], Birkeland [3], Cole [4], Mang and Reed [5] and du Plessis [6,7], the call has gone out for approaches that facilitate built environment outcomes that move beyond marginal improvements and shift our focus towards creating vitality and net benefit. Projects that begin to heal the damage done in the past and consider creating vital relationships that lead to resilience. Regenerative development can be seen as a process to facilitate this type of approach to contributive development [5,8-11].

Regional development (which occurs in rural or semi-rural communities, outside of major urban centres) presents a clear opportunity where regenerative development can be applied. The case study investigated in this paper aimed to become a net positive living environment, defined as "a setting that is thriving, healthy, and resilient because its ecological, social, and economic systems are continually nourished" ([12], p. 2), using a regenerative development defined as "the process of cultivating the capacity 
and capability in people, communities, and other natural systems to renew, evolve, and thrive" ([12], p. 2). Though in its infancy in application, Regenerative Development draws on the fields of knowledge required to better understand the "unique social, cultural and ecological opportunities and constraints of place" ([4], p. 48), including history and natures wisdom [13], and provides alternative ways to look at development. Regenerative development focuses on symbiosis with nature, in contrast to most other forms of development which can focus on other aspects. Critically, regenerative development aims to work within a system to enable the potential of the system to emerge; to co-evolve the aspects of the system so that it can constructively adapt to change and evolve towards increasing states of health and abundance. This typically involves a shift in mindset that puts thinking about potential before problem-solving [5].

Currently, there are examples of the application of regenerative development ideas but these tend to be reflections on projects and their outcomes [5]. Examples include case studies found on practitioner pages such as Regenesis and the Institute for the Built Environment (IBE) at Colorado State University. While these provide insights into the outputs of regenerative development projects, there is a need to better understand the process that supports regenerative thinking and contrasting it to "business as usual". In other words, how do we operationalise these abstract concepts of creating ecological, social and economic benefits to achieve a living environment?

\subsection{Aim and Scope}

The aim of this paper is to assess the process of applying regenerative thinking and reflect on the outcomes for the participants and the design of the masterplan of a 680-hectare project, "Seacombe West", in Gippsland, Victoria, Australia, $217 \mathrm{~km}$ southeast of Melbourne. The framework that was used to facilitate the design of the Living Environment was the LENSES (Living Environments in Natural, Social and Economic Systems) framework. This paper discusses how this case study and its three-months design process drove the ability to move towards regenerative development. This was achieved by comparing the 2003 failed masterplan with the outcome of the LENSES Framework application; evaluating the effectiveness of the LENSES Framework to guide the outcome towards a healthier and more ecological built environment (through a survey); investigating how both the approach and the framework, together with transdisciplinary collaboration provided a pathway and a model to support future projects (through semi-structured interviews and the survey); and lastly, assessing if there were significant lessons, enablers and benefits drawn from the process. As such we outline the process of designing for building upon the potential of the site, detail the application of the LENSES Framework, present the results of the design, and report on the interviews and surveys undertaken with the participants involved in the design process. The scope of this paper is depicted in Figure 3.

To summarise, this project is a step along the way to understanding how transdisciplinary collaborations can create net benefit. It provides a potential foundation for future evaluation and research around the project. The investigation into the design process was guided by the following key questions:

- Is the process used in this project justified in terms of investment in time, energy and resources?

- Does it have the potential to achieve Regenerative Regional Development?

- What worked well?

- What could have been improved?

- What were the key enablers?

\subsection{Case Study Area}

Seacombe West is located $217 \mathrm{~km}$ southeast of Melbourne in Victoria, Australia. The proposed 680 hectares $\left(6.8 \mathrm{~km}^{2}\right)$ development is located south of Lake Wellington (or Lake Murla in the Indigenous Gunai language), which is one of the three major interconnected lakes that form the 
Gippsland Lakes systems (Figure 1). The lakes cover $340 \mathrm{~km}^{2}$ and are separated from the Bass Strait by a linear sand shore that forms the Ninety Mile Beach. The lakes are fed by seven rivers that carry water from a catchment area of 20,000 km² [14]. The Gippsland Lakes system is listed as a Ramsar site under the Ramsar Convention of 1982 in recognition of its outstanding coastal wetland value and natural features [15] and is also covered by other wetland and bird protection agreements. The site is now seen as meeting six out of the nine nomination criteria recognising its representative wetland habitats at an international level [16].

Equal to the site's natural significance, the Gippsland Lakes embody diverse cultural and socio-economic values in the State of Victoria by generating economic activities in the form of agriculture, fishing, boating and tourism. There is an increasing pressure on urban nodes and small fishing communities from population growth, recreational fishing and boating, as well as holiday tourism. The Gippsland Lakes also present a long Indigenous history well before the European settlement in the 1830s. The Gippsland Lakes "fall within the boundaries of the area occupied by the Tatungalung clan of the Gunai/Kurnai people" (Parks Victoria 2009a). Sadly, Indigenous history in Gippsland is one of massacre [17], displacement and disconnection. The involvement of a local elder in the project was therefore seen as critical to be able to have their voice contribute to the outcomes.

The lakes were permanently connected to the sea at Lakes Entrance in 1889 through an artificial channel. The introduction of the artificial entrance drastically altered the existing freshwater hydrology, causing chronic salinisation and significant changes in water levels within the lakes [18]. Lake Wellington is the least saline of the three lakes [19]. However, its biodiversity has rapidly declined over the last decades [17]. The salinity at the Seacombe West site has also increased due to reductions in lake inflow caused by agriculture and the development of numerous dams within the lake's catchment. After each flooding, a layer of salt is often left on the land. As a result, the site can no longer serve its past ecological or farming functions.

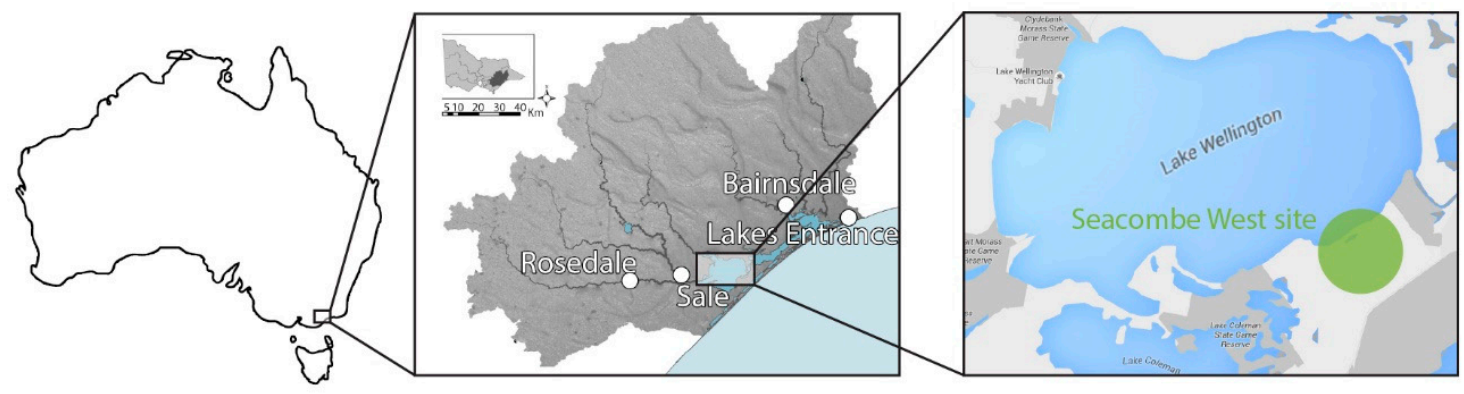

Figure 1. The Gippsland Lakes catchment area and the location of the site on the south-eastern shores of Lake Wellington (Lake Murla). Adapted from Love Our Lakes [20] and Google Maps ${ }^{\circledR}$.

The proposed development intends to work with the changed saline conditions and provide stable habitats while regenerating the ecological functions of the degraded ecosystems. A multifaceted development based on a range of sustainability principles was the starting point. The application of regenerative development thinking to the project's development aimed to enhance the ecological, social and economic performance of the site.

\section{Evaluating the Regenerative Design Process}

This section presents the method used to evaluate the LENSES Framework, its ability to support regenerative design approach, and living environment outcomes. It starts by reflecting on the aim to achieve net benefit. The following sections detail the overall research method and the series of workshops conducted as well as how the outcomes of the design charrette were evaluated. Finally, the online survey and the semi-structured interviews used to evaluate the experience of participants are presented. 
No definition will completely capture what is needed to create benefits for a project. What the above definition for Regenerative Development (see Section 1) tries to encapsulate is the ability to create mutually supportive relationships-ecosystems nourished by social systems, nourished by economic systems, nourished by ecosystems, and so forth. This is achieved through understanding what aspects of the social, ecological and economic systems flow through the project. Regenerative development through the LENSES Framework takes these aspects and considers their constituting flows. Flows are what brings a place to life (e.g., air, water, nutrients, etc.). Regenerative development asks project teams to look at how their designs can create opportunities for these flows to connect and support increased vitality, viability and adaptability.

The difference of water in a pipe and water meandering through the site is a commonly used example to describe these three notions. Both the pipe and the stream are flows of water, but only one creates the potential for relationship with the systems around it. This relationship can be negative-where, for example, the water is used as a place to dump waste, is polluted, over fished, or used to irrigate the land around it to the point that it cannot self-sustain. Alternatively, the relationship can be positive-with water providing cooling, habitat, recreation, beauty, or a place for social activities. Viability is the ability to work, to survive and live successfully [21], while vitality is strength and the capacity for survival and the continuation of a meaningful and purposeful existence. In the water example, the water is healthy, clean, with consistent capacity (it is viable), so it provides a vital contribution to the ability of other flows in the system to be healthy-people, animals, plants and other living organisms. Both viability and vitality contribute to the system's ability to be adaptable, creating positive feedback loops that support the whole to be stronger.

Measuring the capacity to enhance vitality, viability and adaptability is critical and needs to be further developed, as many of the things that are most valued (e.g., increased social cohesion and love of a place because of a waterway) cannot always be quantified or measured. Therefore, when looking at the design of a living environment, it is not just about the quantification of increased species, social measures, food production, ecosystem services, etc. It is about the ability for a project to thrive and continue to evolve into the future, and for unexpected opportunities to emerge. Much of this can only be evaluated retrospectively and through story and experience. Specifically, for this case study, the main aims of this Living Environment are:

- to partly restore the fresh water habitat that supports over 80 species of water birds, which no longer stop at the site;

- to contribute socially;

- to safeguard pest free areas for indigenous species;

- to build a safe harbour for visitors to the lake;

- to contribute to the vitality of the local economy;

- to build human habitat with minimal impact;

- to cover the operational energy demand through renewable energy sources;

- to produce food locally; and

- to provide a model for future development that challenges the development practice.

To achieve these aims, a transdisciplinary approach was used in the design process, a critical aspect of regenerative development. As Jahn, et al. [22] defined, a transdisciplinary approach is:

"a critical and self-reflexive research approach that relates societal with scientific problems; it produces new knowledge by integrating different scientific and extra-scientific insights; its aim is to contribute to both societal and scientific progress; integration is the cognitive operation of establishing a novel, hitherto non-existent connection between the distinct epistemic, social-organizational, and communicative entities that make up the given problem context". ([22], p. 8) 
As Hoffmann, et al. [23] noted:

"the definition emphasizes the importance of integration at epistemic, social-organizational, and communicative levels in order to reach both societal and scientific progress". [24]

In other words, transdisciplinarity can be considered as working collaboratively and scientifically to produce solutions that transform all involved. Everyone engaged with the project can expect to learn from every other participant—be they professor, elder or child; architect, engineer or scientist; artist, or the site itself.

\subsection{The LENSES Framework}

The LENSES Framework was used to document the flows for this project and design opportunities for flows to interact and relate. The aim of this framework is "to facilitate tangible, actionable and contextually based solutions that support and create healthy, natural, social and economic system" ([25], p. 113). As depicted in Figure 2, the LENSES Framework is represented by a circular disk that consists of a series of overlaid lenses, each representing a level of information. The outermost lens (the Foundation Lens) outlines the guiding principles of the project. The intermediate lens (in blue) is the Flows Lens and represents the range of flows across the project. These can be physical or abstract. Both the flows and the guiding principles of the project were defined by the stakeholders during Workshops 1-3 (see Figure 3). The blank allows for the emergence of additional flows/guiding principles to be added. In the centre of the framework is the Vitality Lens which contains the two spheres of degenerative and regenerative design and prompts the workshop participants to think about how to create opportunities for interaction between flows, create benefit for a flow, and to think about that in context of the key guiding principles. The lenses were made into an interactive artefact used by participants to prompt their creativity. This visual representation of the framework and the fact that it was based on the principles and flows of the place, helped participants structure their thinking during the workshops. Beyond its visual representation, the LENSES Framework condenses the essence of the project in terms of flows and intentions. This greatly facilitated working in groups made of many disciplines and points of view, and allowed innovative ideas to emerge and be developed that were beyond the expectations of the project team.

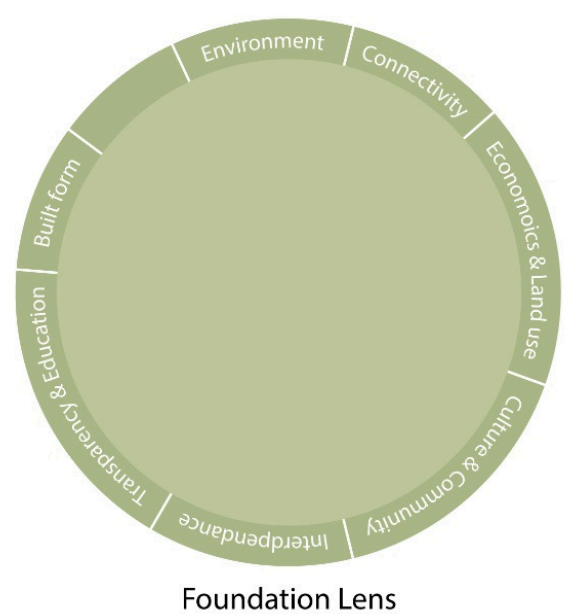

(a)

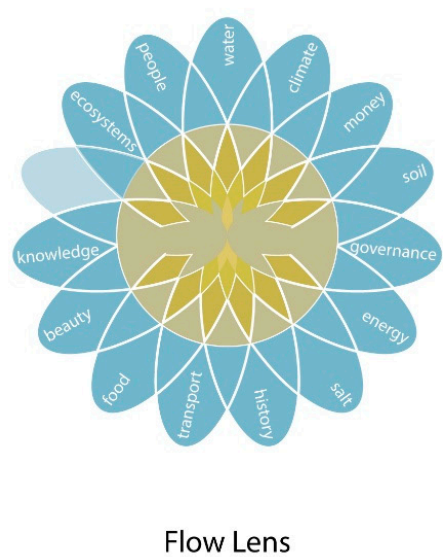

(b)

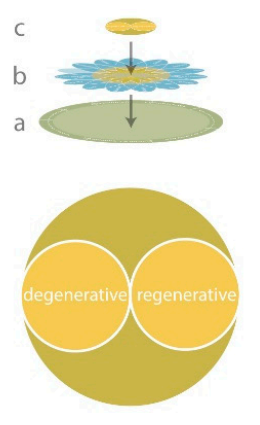

Vitality Lens

(c)

Figure 2. Visual representation of the LENSES Framework, adapted to the Seacombe West project. Note: (a) is the foundation lens which summarises the essence of the project, its key objectives; (b) is the flows lens which summarises the flows that bring a place to life while the Vitality lens; (c) is a prompt to always develop relationships between the flows and the place to as to achieve the objectives and create increased vitality and viability in the system; colours are the original colours of the LENSES framework and do not serve a particular function beyond contrasting. 


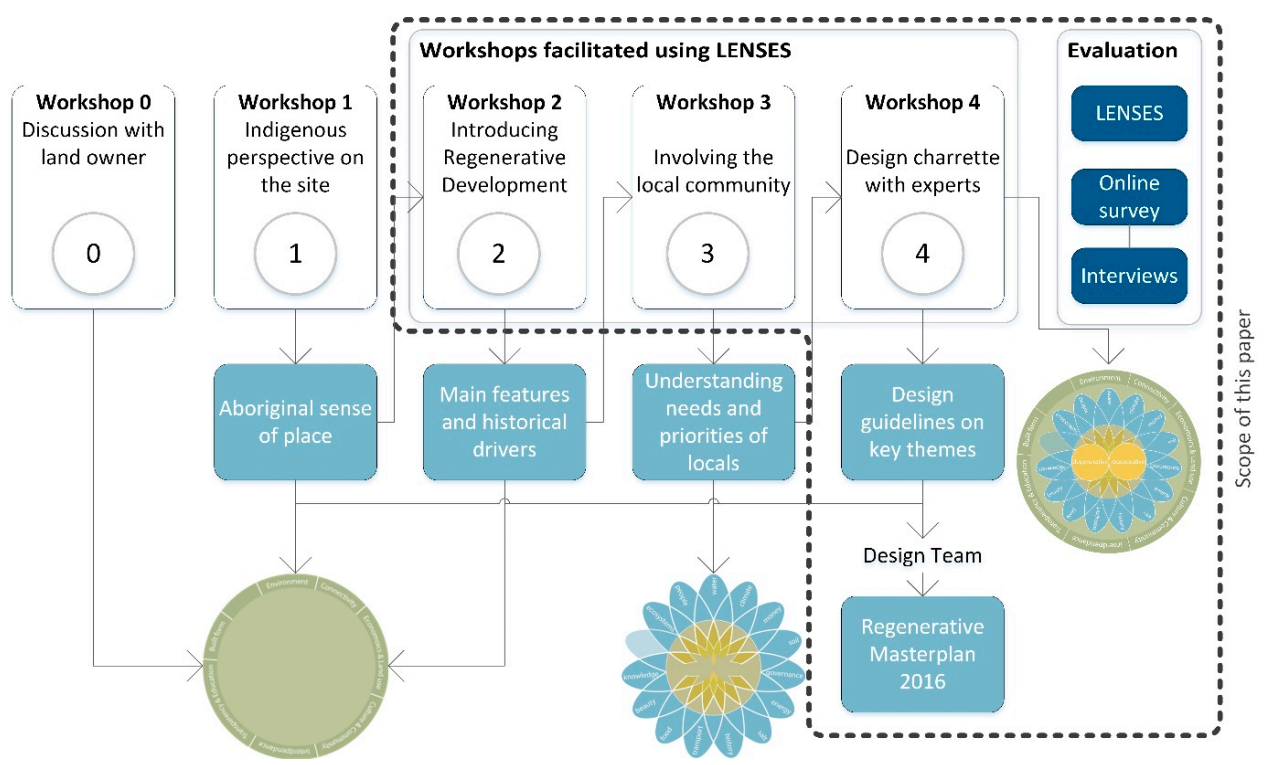

Figure 3. Overall process of the project and scope of this paper. Note: colours are the original colours of the LENSES framework and do not serve a particular function beyond contrasting.

Beyond Seacombe West, the LENSES Framework has been used to drive regenerative outcomes in projects as diverse as town planning, building design, education, personal growth and organisational development. This supports its polyvalence. Yet it is not the only tool or framework for supporting regenerative type thinking; there are others (e.g., EcoBalance, Living Building Challenge, Perkins+Will Framework, REGEN (not active)). Within the context of other frameworks supporting the development of sustainable buildings and communities, the LENSES Framework helps identify which tools will support the outcomes that the project seeks. For example, at the building level, these tools can be the Living Building Challenge, LEED, BREEAM or Green Star. As such for Seacombe West the certification tool investigated is One Planet Living. The aim of using LENSES is not certification, nor reporting, it is a way to facilitate initial thinking and planning about the potential of a place by looking deeply at the flows that could bring greater vitality to the systems. As such, categories (e.g., energy, water, internal environmental quality, materials, waste, etc.) are not defined as they are in tools such as LEED, Green Star, One Planet Living and BREEAM. They emerge by engagement with the land, its people, and its history. The LENSES Framework also uses the process of identifying what brings a place to life in order to define principles for achieving certain outcomes for a place. Using the identified flows and defined principles, certification tools are identified and used if desired by the user group.

Further the LENSES Framework does not set targets for each flow or category (e.g., Hammarby Model energy reduction by $50 \%$ ). The aim of a regenerative development is to identify, to the greatest extent possible, the potential for system evolution. It acknowledges that any development impacts the land and has direct and indirect environmental effects, but asks how to best use these to create social and ecological restoration, as well as increase vitality and viability of the project area and the greater system in which it is nested.

Therefore the LENSES Framework was chosen for its ability to capture what we considered the key elements needed to develop a design in a regenerative manner and produce living environments. Plaut, Dunbar, Wackerman and Hodgin [25] provide a detailed explanation of the framework and readers are referred there for more information. In this paper, we have also used the flows lens as an analytical tool to qualitatively evaluate the design guidelines that emerged from Workshop 4, as presented in Section 3.1. 


\subsection{Overall Research Method}

The authors led and organised a series of workshops with the key stakeholders of the project in order to facilitate regenerative thinking from the early stages of design. The results of each workshop were carried forward to the next, as depicted in Figure 3. The fourth and final workshop consisted of a design charrette over 2 days, with 40 participating experts in fields including water management, engineering, landscape architecture, architecture, construction, governance, biology, sociology, economics, visual and performing arts. Indigenous, government, local community and youth representatives were also present. This workshop was facilitated by Professor Brian Dunbar, one of the creators of LENSES. It generated design guidelines, concepts, opportunities and ideas that were provided to the design team for consideration in designing the masterplan.

As shown in Figure 3, this paper evaluates (1) the transfer of regenerative thinking from Workshop 4 to the design guidelines; and (2) the translation of these guidelines into the masterplan. This evaluation will test whether using a regenerative thinking through the LENSES Framework to facilitate the workshops (see Section 3.3) supports guidelines that match the systems thinking on which it is based. Furthermore, discussing if these guidelines are in turn reflected in the final masterplan can help reveal if outputs from the workshops were taken on board by the design team or if a business-as-usual mentality prevailed.

\subsection{Description of Workshops}

This section outlines each of the workshops, including the two-day design charrette. Table 1 chronologically presents the workshops and main events of the project.

Table 1. Description of the workshops' aims, participants, activities and final outputs.

\begin{tabular}{|c|c|c|c|c|}
\hline Workshop/Event & Aim & Stakeholders & Activities & Outputs \\
\hline $\begin{array}{l}2015 \\
\text { Prework—at the site }\end{array}$ & $\begin{array}{l}\text { Identify the } \\
\text { principles of the } \\
\text { project }\end{array}$ & Land owners & $\begin{array}{l}\text { Used the Vitality Lens to } \\
\text { discuss the shift from } \\
\text { degenerative to regenerative } \\
\text { design; and the Foundation } \\
\text { Lens to develop an initial } \\
\text { understanding of regenerative } \\
\text { development principles. }\end{array}$ & $\begin{array}{l}\text { Key principles: } \\
\text { Interdependence } \\
\text { Stewardship } \\
\text { Respecting limits } \\
\text { Partnership } \\
\text { Transparency and education }\end{array}$ \\
\hline January 2016 & Team formation & $\begin{array}{l}\text { Group of } \\
\text { researchers }\end{array}$ & $\begin{array}{l}\text { Shared the potential of the } \\
\text { project for an internal } \\
\text { research grant. }\end{array}$ & Received grant \\
\hline $\begin{array}{l}\text { February } 2016 \\
\text { Workshop } 1 \text {-at the } \\
\text { UoM }\end{array}$ & $\begin{array}{l}\text { Cultural } \\
\text { Awareness } \\
\text { Training }\end{array}$ & Design team & $\begin{array}{l}\text { Team taken through } \\
\text { Indigenous history and design; } \\
\text { and, the way to be sensitive } \\
\text { and effective communicators } \\
\text { to the Indigenous community. }\end{array}$ & $\begin{array}{l}\text { Deeper understanding and } \\
\text { inclusion of indigenous } \\
\text { lore/history. Started using } \\
\text { the Indigenous timeline as } \\
\text { basis for the history of place } \\
\text { activities (see Workshop 2). }\end{array}$ \\
\hline $\begin{array}{l}\text { February } 2016 \\
\text { Workshop } 2 \text { at the } \\
\text { UoM }\end{array}$ & $\begin{array}{l}\text { Understand } \\
\text { LENSES and } \\
\text { Regenerative } \\
\text { education }\end{array}$ & Design team & $\begin{array}{l}\text { Three hour introduction to } \\
\text { regeneration (Vitality) and the } \\
\text { LENSES process, and started } \\
\text { the Flows Analysis through a } \\
\text { history timeline activity } \\
\text { (Flows across time). }\end{array}$ & $\begin{array}{l}\text { Shared understanding of the } \\
\text { potential of the site and the } \\
\text { regenerative design process }\end{array}$ \\
\hline $\begin{array}{l}\text { February } 2016 \\
\text { Site visit }\end{array}$ & Site familiarisation & $\begin{array}{l}\text { Design team } \\
\text { and researchers }\end{array}$ & $\begin{array}{l}\text { A whole day visit of the } \\
\text { site-visited } 4 \text { areas of the site } \\
\text { and collected drone footage }\end{array}$ & $\begin{array}{l}\text { Ability to connect to the } \\
\text { issues of the site, input into } \\
\text { the Flows Lens }\end{array}$ \\
\hline $\begin{array}{l}\text { March } 2016 \\
\text { Workshop } 3 \text { onsite }\end{array}$ & $\begin{array}{l}\text { Community input } \\
\text { and site visit, } \\
\text { drawing from both } \\
\text { the key flows }\end{array}$ & $\begin{array}{l}\text { Community } \\
\text { (around } 20 \\
\text { participants) }\end{array}$ & $\begin{array}{l}\text { Site visit, followed by a } \\
\text { two-and-a-half-hour } \\
\text { workshop around: "What is } \\
\text { important to the community"? }\end{array}$ & $\begin{array}{l}\text { Ability to connect to the } \\
\text { issues of the site, input into } \\
\text { the Flows Lens }\end{array}$ \\
\hline
\end{tabular}


Table 1. Cont.

\begin{tabular}{|c|c|c|c|c|}
\hline Workshop/Event & Aim & Stakeholders & Activities & Outputs \\
\hline $\begin{array}{l}\text { March } 2016 \\
\text { Workshop } 3 \text { at the } \\
\text { local council }\end{array}$ & $\begin{array}{l}\text { Community and } \\
\text { government input, } \\
\text { drawing from both } \\
\text { the key flows }\end{array}$ & $\begin{array}{l}\text { Community, } \\
\text { government } \\
\text { and design } \\
\text { team-12 } \\
\text { participants }\end{array}$ & $\begin{array}{l}\text { Repetition of the above with } \\
\text { an additional three hour } \\
\text { workshop: "What are the } \\
\text { critical flows and relationships } \\
\text { we need to develop to ensure } \\
\text { the place has the potential to } \\
\text { thrive"? }\end{array}$ & $\begin{array}{l}\text { Ability to connect to the } \\
\text { issues of the site, input into } \\
\text { the Flows Lens-this } \\
\text { finalised the Foundation } \\
\text { Lens, and the Flows Lens }\end{array}$ \\
\hline 2016 April/May & $\begin{array}{l}\text { Introduce } \\
\text { outcomes of first } \\
3 \text { workshops to the } \\
\text { design team }\end{array}$ & Design team & $\begin{array}{l}\text { Developed design concepts } \\
\text { and finalising principles } \\
\text { and flows. }\end{array}$ & Initial design ideas \\
\hline $\begin{array}{l}\text { April } 2016 \\
\text { Workshop } 4 \text { at the } \\
\text { UoM-2 days }\end{array}$ & $\begin{array}{l}\text { Develop design } \\
\text { directions with } \\
40 \text { experts, industry } \\
\text { and community }\end{array}$ & $\begin{array}{l}40 \text { industry and } \\
\text { research } \\
\text { experts }\end{array}$ & $\begin{array}{l}\text { Developed regenerative ideas } \\
\text { integrated across building, } \\
\text { infrastructure, ecosystem, } \\
\text { water, land, governance, } \\
\text { community \& innovation. }\end{array}$ & $\begin{array}{l}\text { Participants identified } \\
\text { opportunities and gaps in } \\
\text { the knowledge to further } \\
\text { inform the research agenda }\end{array}$ \\
\hline $\begin{array}{l}\text { April-May } 2016 \\
\text { Online Survey } \\
\text { Online survey }\end{array}$ & $\begin{array}{l}\text { Collect participants } \\
\text { feedback }\end{array}$ & $\begin{array}{l}40 \text { industry and } \\
\text { research } \\
\text { experts }\end{array}$ & $\begin{array}{l}\text { Filled in an online survey } \\
\text { consisting of } 10 \text { questions that } \\
\text { cover their experience of } \\
\text { the Workshops. }\end{array}$ & $\begin{array}{l}\text { Participants feedback on } \\
\text { the workshops }\end{array}$ \\
\hline $\begin{array}{l}\text { August } 2016 \\
\text { Interviews } \\
\text { Interviews }\end{array}$ & $\begin{array}{l}\text { Collect key } \\
\text { stakeholder } \\
\text { feedback }\end{array}$ & $\begin{array}{l}\text { Client, chief } \\
\text { architect and } \\
\text { chief landscape } \\
\text { architect }\end{array}$ & $\begin{array}{l}\text { Filmed semi-structured } \\
\text { interviews with the } \\
\text { stakeholders. }\end{array}$ & $\begin{array}{l}\text { Key stakeholder's feedback } \\
\text { on the workshops }\end{array}$ \\
\hline
\end{tabular}

Note. UoM: University of Melbourne.

Workshop 2 gathered the design team at the University of Melbourne in order to introduce its members to the LENSES Framework. It allowed the design team to get acquainted with the regenerative development framework and LENSES as well as generate a common base understanding of the potential of the site.

Workshop 3 included two sessions. One with the community and indigenous elders on the site and the other with the community, industry and the government in the closest town. These sessions were critical to create the final masterplan. The two locations were chosen to generate maximum outreach to potential stakeholders. These two sessions of workshop 3 followed a similar format, each working with the participants to think about the history of the site and the area and how the site had changed. This allowed identifying and refining what flows should be considered. These flows provided the foundation for workshop 4 .

Workshop 4 consisted of a two-day design charrette and is outlined in more detail. Critically, the two days started with an outline of the limitations of the mainstream linear and mechanical worldview approach to development. This was balanced by showing how over the last 30 years projects have started to emerge to challenge this linearity such as BedZED, Eva Lanxmeer [10], and many of the eco-city, Living Building Challenge type projects. Regenerative development was introduced as a way of working in this new worldview (see for example Goldsmith [26], Rees [27], Capra [28], Sterling [29] and Bourne [30]).

The participants were divided into groups matching a domain of the Seacombe West project:

1. Built Environment-housing, building design, site plan;

2. Ecosystems—analysing, regenerating the natural systems;

3. Land; Water-design, considerations for regen development;

4. Governance; People; Money; Culture-thrive, live, play, govern; and

5. Inspiration-thriving economy, culture, music, art, entrepreneurship.

The project was introduced to these groups, including the principles of the foundation lens identified in workshop 3 . Three groups (1,2 and 5) were asked to imagine the project failing in 10 years 
in the future and describe the reasons behind this failure. The other two groups ( 3 and 4 ) were asked to imagine the project's success and its drivers. The two groups then swapped and built on the work of the previous group. This led to a discussion of how one could imagine supporting successes and minimising the reasons for failure.

The five groups were then asked to consider the principles underpinning the design of the site and the flows lens was introduced. Each group was asked to determine the key flows that could bring benefit to their domain, and then to look at an existing rubric of shifting the flows from degenerative to regenerative. These rubrics are a key tool of the LENSES Framework that allow participants to imagine what achieving more than sustainable development could entail. There are 11 rubrics for the flows of beauty, money, ecosystems, water, energy, materials, transport, education and so forth. In the charrette, the use of the rubrics allowed the groups to start brainstorming ideas and design initiatives that could create beneficial relationships for the flows. Critical to the process, and as a result of the calibre of the participants and their experience, ideas generated have a higher potential for success-success in terms of providing vital, viable and resilient outcomes. For example, the proposed approach for developing the waterways was a result of having Victoria's leading fish ecosystems scientist working with a leading sea grass ecologist, hydrologist, geomorphologist and carbon sequestration experts.

The following day started with a recapitulation of what everyone had covered the day before. Each group was then asked to revisit the LENSES artefact and think about the principles and flows considering their group's domain. Additionally, participants were asked to move between groups to cross-pollinate ideas. The groups were then asked to explore the interesting edge opportunities-for example what happens where land meets waterway; what happens where residential area meets community or retail; what about the edges of commercial and education. The rest of the day was spent on developing ideas to the level of resolution that the design team could take forward with a key focus being identifying areas of uncertainty and further research requirements. Each of the five groups then presented the results which are evaluated in Section 3.1 as per the method discussed in Section 2.4.

\subsection{Evaluating the Outcomes of the Design Charrette}

The design guidelines from the design charrette are evaluated in this paper using the Flow Lens of the LENSES Framework. In order to conduct this assessment, the design guideline outputs of each of the five groups of the design charrette (see Section 2.3) were collected. These included both the "poster" that each group presented at the end of the workshop, as well as the recorded video of their presentation. Figure 4 is an example of the posters presented. It has been kept in this form to accurately depict the actual physical outputs produced during the workshop. These outputs were analysed to extract the main ideas and themes. These were then used to map which flows in the Flow Lens were covered by the design guidelines of each group.

To also evaluate if these design guidelines affected the design team and their thinking on the final masterplan, the latter was compared to an earlier masterplan from 2003. The previous masterplan did not involve any regenerative development thinking nor facilitation and therefore provides a benchmark against which the proposed masterplan can be compared. This comparison is conducted across the categories of layout, staging, goals, underpinning thinking and housing strategies. In addition to evaluating the outcomes of the workshops, the experience of the participants is also assessed by evaluating responses to an online survey and semi-structured interviews, as described in Section 2.5. 


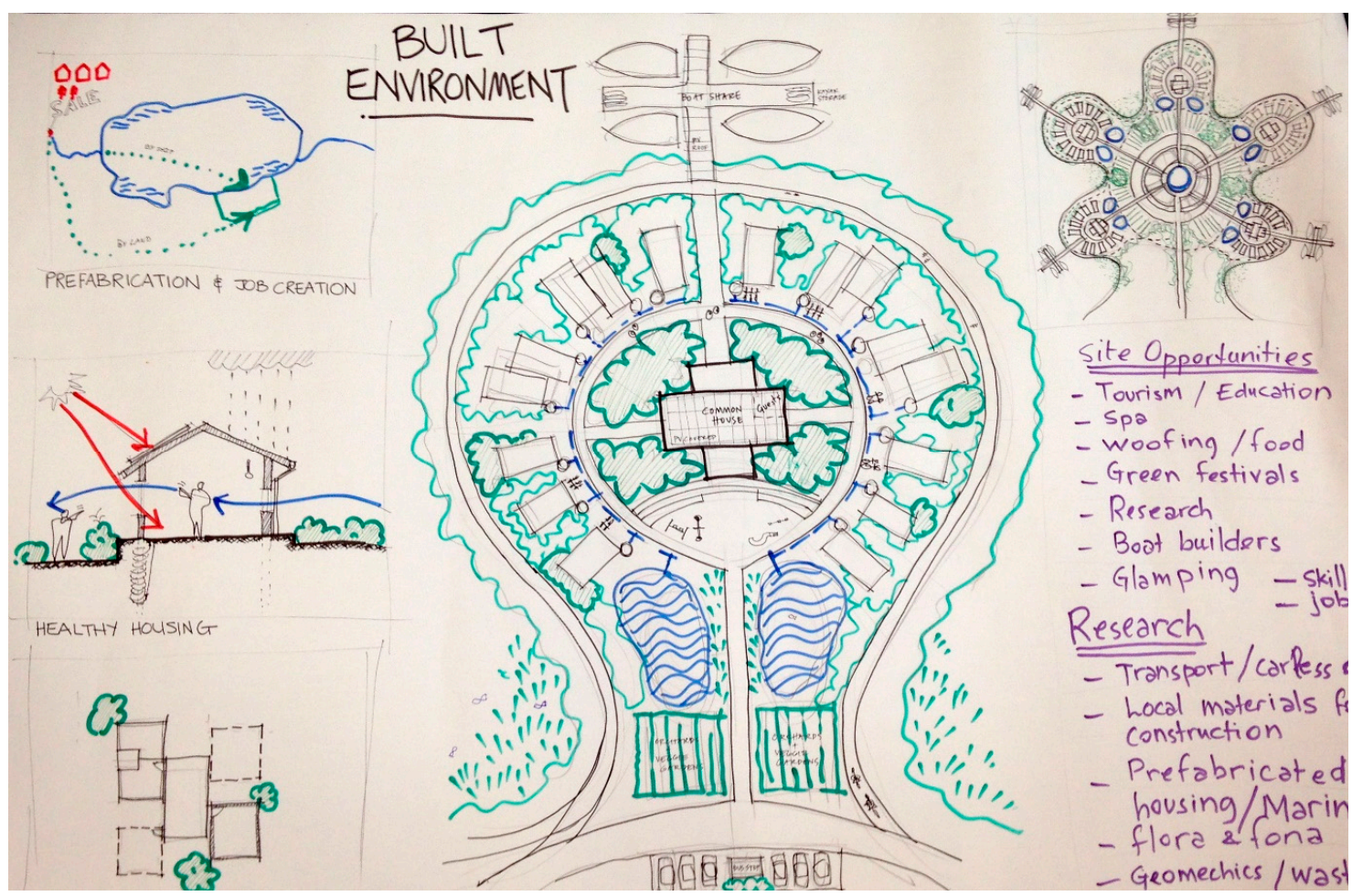

Figure 4. Poster of the design guidelines of the Built Environment group, produced at the end of Workshop 4-Design Charrette (source: Authors).

\subsection{Evaluating the Experience of Participants}

This section describes how the experience of the participants was evaluated. It first presents the online survey used, followed by the semi-structured interviews.

\subsubsection{Online Survey}

To assess the participants' perception of the LENSES Framework as a facilitation tool that enabled regenerative thinking, an online survey was devised and distributed. The survey comprises a set of ten questions, which are listed in Appendix A. In summary, the survey included:

- questions regarding the role of the participants and their attendance;

- $\quad$ Likert-scale (7 options, see Table A1) questions on personal gain from the workshops, the benefit to the project from the workshops and the participants' understanding of regenerative development;

- open-ended questions that cover personal gain, defining regenerative development, the benefits of LENSES and the potential improvement to the facilitation process with LENSES: and

- $\quad$ Likert-scale (5 options, see Table A1) with 9 sub-questions evaluating the performance of LENSES on a range of indicators.

The survey was opened to participants from the end of the design charrette (Workshop 4, 12 April 2016) until 31 May 2016 (50 days). Participants were encouraged to take the survey and were reminded twice by email, an established booster to response rates [31]. Although, participation in the survey was facultative, 28 responses were collected out of 40 stakeholders involved in the workshops (most of whom were present during the design charrette-Workshop 4). The resulting response rate of $28 / 40=70 \%$ is much higher than average response rates to online surveys as reported by Nulty [31] (33\%) and Baruch and Holtom [32] (38.9-54.7\%). However, the sample size was not very large and this is further discussed in Section 4 . All survey questions were approved by an ethics committee and 
all participants were informed of the project, data collection and survey participation through a plain language statement distributed during the workshops as well as face-to-face explanations.

\subsubsection{Semi-Structured Interviews}

The online survey was complemented by semi-structured interviews with key stakeholders. The aim of the interviews was to extract additional information regarding the workshops and the use of the LENSES Framework. In this regard, the interviews should be regarded as supplementary data that is used to reinforce certain trends observed in the survey, instead of another source of data that is thoroughly analysed. For this reason, the results section does not include a separate analysis of the responses to interviews. These are used to bring the voice of the participants into the discussion, through the use of quotes. The list of questions used in the interviews is provided in Appendix B.

The interviews targeted the client, the chief architect and the chief landscape architect of the project. All interviews were conducted on the 11 August 2016 at The University of Melbourne and were recorded on video for further analysis.

\section{Results}

This section presents the main two analyses of the regenerative process: (1) the effect of the LENSES Framework on the design process; and (2) how this process was perceived among the stakeholders. Focusing on how the framework was used and how it informed the design process, we identify the main design guidelines that resulted from Workshop 4, the design charrette, and link them to different flows in the LENSES Framework. Secondly, we compare the original masterplan from 2003 with the one resulting from the regenerative process. Finally, results from the online survey of participants are presented.

\subsection{Summary of Design Inputs as a Result of the LENSES Process}

Results from the analysis of the design guidelines proposed by the six different groups participating in Workshop 4 showed a broad coverage of flows in almost every group. Out of the 15 flows developed with all the stakeholders for this projects LENSES artefact, the identified flows that were covered by each group for a given theme ranged from $5 / 15(33 \%)$ to $13 / 15(87 \%)$ with an average of 9.6 flows (64\%) covered across the six teams (the median is 9.5 and the standard deviation 2.4). The analysis showed that LENSES facilitated the integration of flows that are not generally considered together in a development project, e.g., knowledge, money, ecosystems, people, transport and water. Table 2 synthesises the design guidelines resulting from each theme and the associated flows from the LENSES Framework.

The analysis reveals a strong tendency for incorporating systems thinking across all groups. This is shown through the breadth of aspects (green flows) covered by each group and the proposed guidelines. This type of thinking is characteristic of regenerative development. It is important to note that the "People, Governance, Money and Culture" group highlighted the need for equity in the project, including affordability. The development should be socially inclusive, enabling people with different income levels to live there and avoid becoming a place for the elite. Furthermore, the group highlighted the need for the landscape to enable an understanding of indigenous history instinctively, to champion this history. This would be complemented by an indigenous centre staffed by indigenous people, hopefully residing on site.

The design guidelines above are not unique. They echo what some other leading projects in the field might propose. The difference might lie in the fact that these guidelines are not generic and universal but are developed from the flows and foundation lenses for this particular site, by a specific group of participants, at a certain point in time. The guidelines are based on what history, data and the local stakeholders have told the team and its interpretation by a large group of people from different disciplines and backgrounds in conversation with this data. 
Table 2. Main design guidelines emerging from the design charrette.

\begin{tabular}{ll}
\hline Group/Theme & \multicolumn{1}{c}{ Main Design Guidelines } \\
& $\begin{array}{l}\text { Improve the quality of the entire site through land works, } \\
\text { including elevating land for development, creating waterways } \\
\text { and separating fresh from saline water and stabilising edges } \\
\text { with landscaping elements to prevent erosion. Inland fresh } \\
\text { water bodies (see also Ecosystems) would support local } \\
\text { ecosystems and biodiversity. Potential solar power } \\
\text { desalination plants with excess freshwater would feed back } \\
\text { into the lake to help reduce salinity. Develop a thriving } \\
\text { boating community. }\end{array}$ \\
\hline
\end{tabular}

Enhance and regenerate the current ecosystem by generating a range of microclimates through different wind exposures and land masses (e.g., islands, secluded spaces, elevated red gums and others), creating fresh water lakes and billabongs within the site, minimising salt intrusions through micro-barrages

Ecosystems with fish gates and creating isolated islands as refuge for fauna and flora. This would be done in conjunction with producing food through submerged algae and aquaponics as well as enhancing knowledge transfer through living labs, interactive workshops and nature interpretation trails. Develop an integrated citizen science culture.

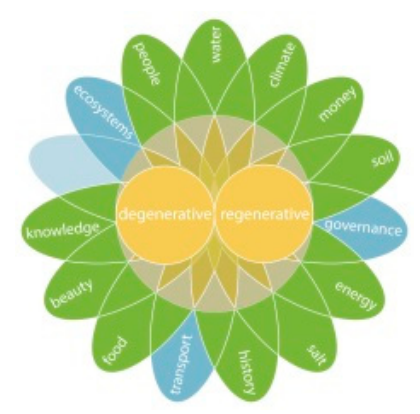

Use a fractal design that is centred on a common house and space where public amenities are provided. Design modular prefabricated, carbon positive homes that are made locally

Built

Environment Planning from local materials where possible. This would encourage job creation and local industries. Devise a car-free environment with cycling lanes, boat sharing, public buses and solar-powered boats. Design buildings as catalysts for development of ecosystem niches.

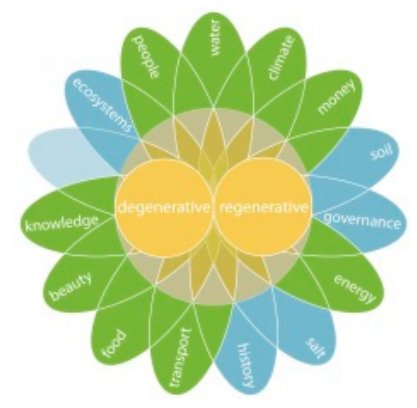

Use a modular and scalable centralised plant that simultaneously treats energy, waste, water, greenhouse gas emissions and other environmental flows. Implement a range of processes, including recycling, composting, urine diversion, a range of renewable energy technologies, waste carbon dioxide and heat used to grow food in greenhouses. Share all data openly to enhance knowledge transfer.

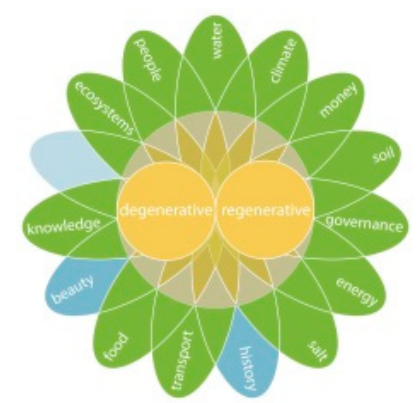

Ensure the presence of innovation and equity in the community. Develop an innovative investment model focused

People Governance Money Culture on experience and crowdfunding, teaching through events, video games and an annual festival of ideas all within a bottom-up participatory governance approach. Enable an instinctive understanding of the Indigenous history and contribution to the site by the simple experience of the place.

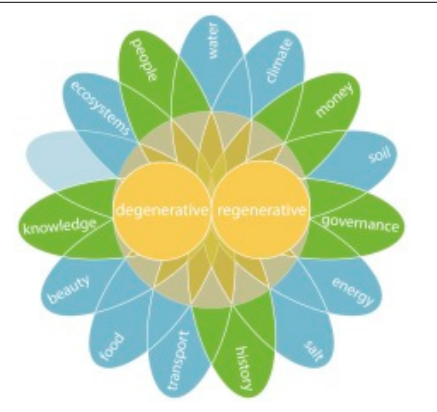


Table 2. Cont.

\begin{tabular}{ll}
\hline Group/Theme & \multicolumn{1}{c}{ Main Design Guidelines } \\
& $\begin{array}{l}\text { Develop a sense of stewardship within the community with a } \\
\text { main focus on contributing to the place, caring for the land } \\
\text { family and for life as well as fostering a collective sense of } \\
\text { responsibility. This would be supplemented by an experiential } \\
\text { learning, a living academy and transdisciplinary } \\
\text { Vision and } \\
\text { inspiration } \\
\text { stakeholders, such as universities, art centres, government, } \\
\text { local industries and others. A particular emphasis is made on } \\
\text { inclusivity, championing Indigenous culture and developing } \\
\text { tolerance of all cultures. Exports would be knowledge, } \\
\text { experience and local products. }\end{array}$ \\
\hline
\end{tabular}

As such, the guidelines can sometimes be aspirational or even unrealistic. However, by setting the bar very high, guidelines can drive the design team to innovate or seek alternative solutions in order to fulfil (some of) the potential of the site. This way, even after budget, time constraints, feasibility and other factors come into play, the remaining design still has the capacity to evolve and improve in the future, following regenerative development principles.

From these observations, it seems that the LENSES Framework can fulfil its aim of facilitating regenerative design workshops by supporting the emergence of systems thinking. This finding is further supported by the comparison of masterplans, and the analysis of survey results.

\subsection{Comparison to the 2003 Masterplan}

The comparison of the 2003 masterplan (Figure 5) with its 2016 counterpart (Figure 6) shows significant differences in the staging, goals and underpinning thinking of the project (Table 3). The 2016 masterplan, delivered by the design team, received the design guidelines emerging from Workshop 4 . The staging of the new masterplan proposes an iterative process through testing a number of concepts before phasing the building works. This staging strategy reflects an experimental design thinking model: testing ideas on the site and evaluating the response, using feedback loops to enhance the subsequent stages as the development unfolds. This underpins an approach that takes into account adaptation measures, meaning that unpredicted outcomes will be integrated in the management and future development of the site, thus helping to support the resilience of the project over time.

Table 3. Comparison of the 2003 and 2016 masterplans of Seacombe West.

\begin{tabular}{|c|c|c|}
\hline Aspect & 2003 Masterplan & 2016 Masterplan \\
\hline Layout & See Figure 5 & See Figure 6 \\
\hline Staging & $\begin{array}{l}\text { Stage 1: The island between the eastern entrance } \\
\text { and the new town centre. "Best blocks first in } \\
\text { best dressed" thinking } \\
\text { Stage } 2 \text { \& subsequent stages: to steadily move } \\
\text { away from Stage } 1 \text { dependent largely on rate } \\
\text { of sales. } \\
\text { Stage 3: including the resort and golf course will } \\
\text { then follow }\end{array}$ & $\begin{array}{l}\text { Stage } 1 \\
\text { Start with one aspect, the safe harbour and } 200 \\
\text { non-permanent homes, initial civil work for safe } \\
\text { harbour and ability to test the concept of raising } \\
\text { the land to support restoration of past ecosystem. } \\
\text { This will then inform how the site can evolve } \\
\text { based on learned lessons. }\end{array}$ \\
\hline Goals & $\begin{array}{l}\text { Create a boating-led development, similar to the } \\
\text { kind of developments at the eastern end of the } \\
\text { Lakes system such as Paynesville. Out of } 11 \text { goals, } \\
\text { the last one was to provide wildlife refuges. }\end{array}$ & $\begin{array}{l}\text { Ecological restoration, ecological reserve, staging to } \\
\text { allow ongoing learning, fresh and saline water areas. } \\
\text { Innovation in finance, ownership and community. } \\
\text { Increasing investment of nutrients and soil building } \\
\text { throughout the site. Washing away the salt over time. } \\
\text { Design of more resilient ecosystems. }\end{array}$ \\
\hline
\end{tabular}


Table 3. Cont.

\begin{tabular}{|c|c|c|}
\hline Aspect & 2003 Masterplan & 2016 Masterplan \\
\hline Layout & See Figure 5 & See Figure 6 \\
\hline $\begin{array}{l}\text { Underpinning } \\
\text { thinking }\end{array}$ & $\begin{array}{l}\text { Farm land which was of poor quality for } \\
\text { agriculture or environment but was suitable for a } \\
\text { canal development to meet boating demand in } \\
\text { early 2000s. Redress the salinity issue resulting } \\
\text { from Lake water inundation, as well as using } \\
\text { funds to provide Wildlife Reserve to preserve } \\
\text { endangered small marsupials. Creating } \\
\text { employment and investment into financially } \\
\text { depressed Wellington Shire. }\end{array}$ & $\begin{array}{l}\text { Asking what can the development do to help the } \\
\text { whole region achieve a higher level of resilience. } \\
\text { Asking if restoration is enough, looking instead to } \\
\text { create vital viable systems. Attempt to consider all } \\
\text { the flows across the site and where they go beyond } \\
\text { its boundaries as well as asking how to create benefit. } \\
\text { Look at ecological systems as a model—such as } \\
\text { creating niches. }\end{array}$ \\
\hline Housing strategy & $\begin{array}{l}\text { Environmentally sustainable design passive, } \\
\text { resource efficient. }\end{array}$ & $\begin{array}{l}\text { Modular prefabricated transportable houses, } \\
\text { life cycle carbon positive }\end{array}$ \\
\hline
\end{tabular}

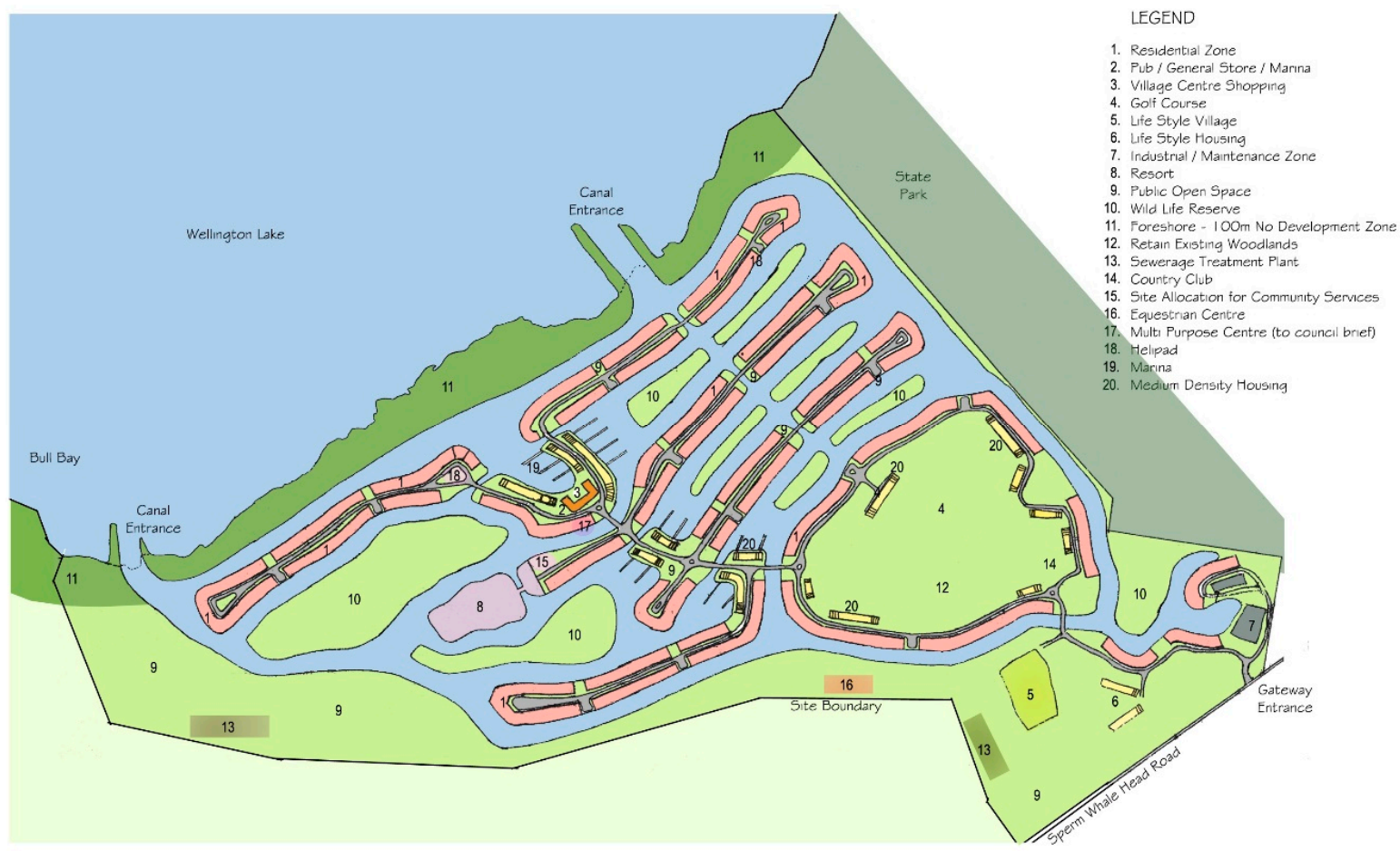

Figure 5. Masterplan of 2003 for the Seacombe West project.

In the earlier masterplan, the goals were mainly developed around socio-economic gains, while the new masterplan is underpinned by restoration and enhancement of ecological and social systems and how the development can result in viable, vital and integrated systems. A number of the guidelines provided from Workshop 4 seem to be taken into account in the underpinning design thinking, notably in terms of enhancing ecosystems and contributing to a healthier environment. Another aspect is the similarity in the housing strategy: the current masterplan proposes "carbon positive" buildings compared to energy-efficient passive housing in the 2003 masterplan. As both of these housing strategies are somewhat at the top-end of what is available on the market in both 2016 and 2003 , it could be argued that technological solutions do not seem to be significantly affected by a regenerative approach. The most technologically advanced solution available at a certain point in time will typically be selected. 




Figure 6. Masterplan of 2016 for the Seacombe West project. Source: [33].

\subsection{Online Survey}

The 28 participants that completed the online survey included 3 architects $(11 \%), 7$ engineers $(25 \%), 6$ scientists $(21 \%), 2$ community members $(7 \%)$ and 10 others $(36 \%)$ who mostly included consultants (4/10) and academics (3/10). The large majority of respondents participated in the design charrette $(86 \%)$ and $14 \%$ participated in Workshop 2. Most responses were provided between 1 and 17 May 2016 (75\%).

Respondents indicated that the attended workshop(s) was/were useful (61\% of responses- $5 / 7$ on the Likert scale) or essential ( $25 \%$ of responses- $6 / 7$ on the Likert scale) to their personal benefit (question 3). The average score was 5.1/7 with a standard deviation of 0.96 and a median of 5/7, revealing that respondents did feel they benefited personally from attending the workshop(s). The free comments in question 4 revolved mostly around the interdisciplinary nature of the design charrette and the positive exposure to the LENSES Framework. Figure 7 summarises the most recurrent words of this comment.

The respondents felt that the project gained useful (5/7 on the Likert scale) to essential (6/7 on the Likert scale) value from the workshops (question 5). On average, they rated the added value 5.5/7 with a standard deviation of 0.79 and a median of $5.5 / 7$. This shows that most participants valued the contribution of the LENSES Framework to the Seacombe West project.

Most respondents indicated that they understood regenerative development in question $6(14 \% a$ little (4/7), 39\% enough (5/7) and $\sim 46 \%$ a lot (6/7)). The average score was 5.32/7 with a standard deviation of 0.72 and a median of $5 / 7$. When asked about defining regenerative development in their own words (question 7), some of the most recurring keywords used included environment (11 responses), positive (8 responses), system (7 responses) and human (5 responses). All of these keywords do belong to the overall regenerative development lexicon $[8,10]$. Figure 8 summarises responses to question 7 . 


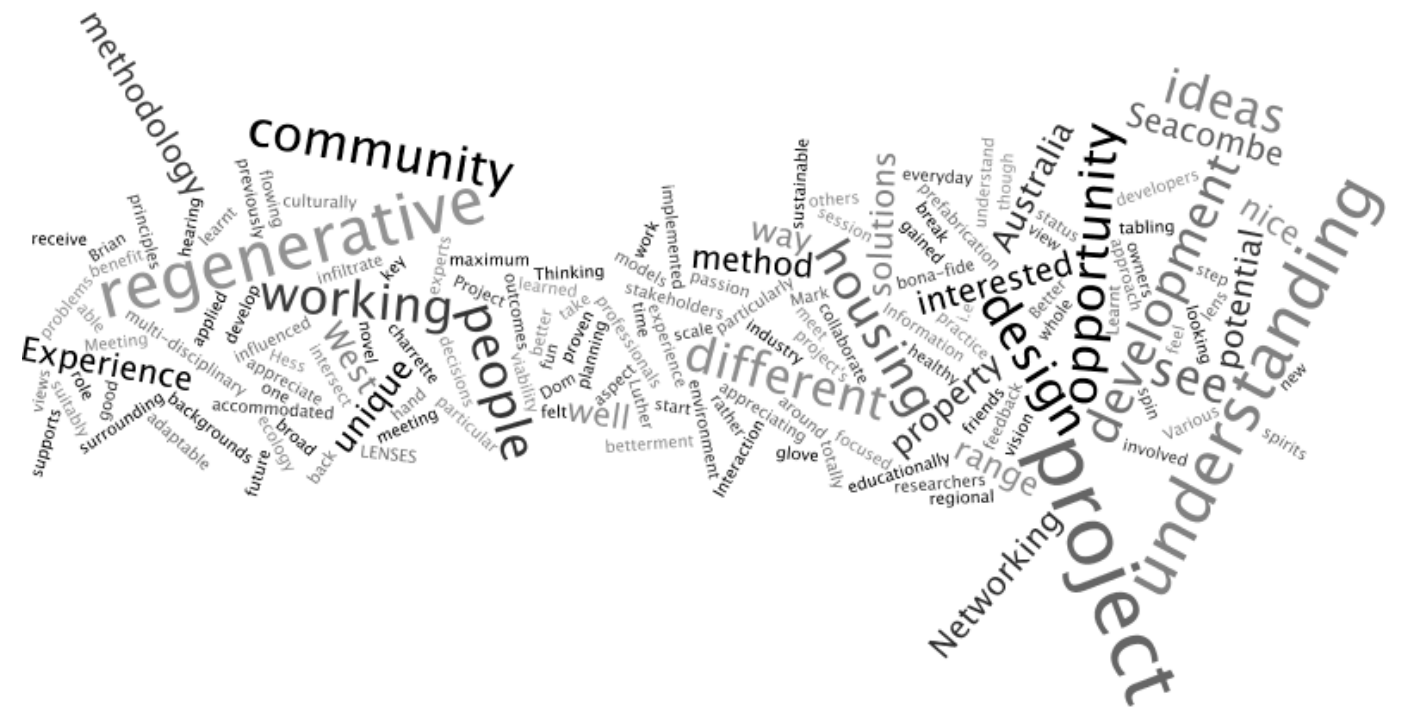

Figure 7. Word cloud summarising the responses to survey participants to question 4: What did you gain from attending? (Source: Authors and Wordle).



Figure 8. Word cloud summarising the responses of survey participants to question 7: In your own words, how would you describe regenerative development? (Source: Authors and Wordle).

Answers to question 8 (see Figure 9) show that the majority of the respondents thought positively about the LENSES Framework capacity to support the design of a Living Environment with most of the scores being 3 or above (out of 5) across the different aspects evaluated. The internal consistency of the responses, represented by the Cronbach Alpha coefficient, is excellent, with $\alpha=0.98$. The lowest average score (3/5) was attributed to the capacity of future-proofing the development while the highest score $(4 / 5)$ was linked to both its capacity to develop a shared understanding of the potential for regenerative development and its support for cross-disciplinary collaboration. The largest standard deviation (1.14), or the question on which most respondents disagreed, was observed for question $8 \mathrm{f}$ regarding the capacity of the LENSES Framework to facilitate/accelerate decision-making. This is $34 \%$ higher than the lowest standard deviation, observed for question $8 \mathrm{~b}$ targeting the capacity of the LENSES Framework to identify key relationships.

When asked about the benefits of using the LENSES Framework (question 9), a strong focus was made on its ability to discuss the topic broadly, providing a more "holistic approach" (respondents 10 and 22). The most used words by the respondents included different (7), flows (5), thinking (5), understanding (4) and relationships (4), highlighting some of the key features of regenerative development (see Section 1 and Figure 10). These reaffirm the high scores received in question 8 on the ability of LENSES to develop a shared understanding through a cross-disciplinary collaboration. In contrast, the major limitation of the process and what could be improved in the view of most respondents (question 10), was the amount of time provided to better understand the LENSES Framework. This is highlighted by the word time appearing in 10 different responses. That view was echoed in the interview with the client who answered the interview question 8 about how to improve the workshops by: "I think we all would have loved to have more time, but as consultants we're all short of time so that makes it hard". 


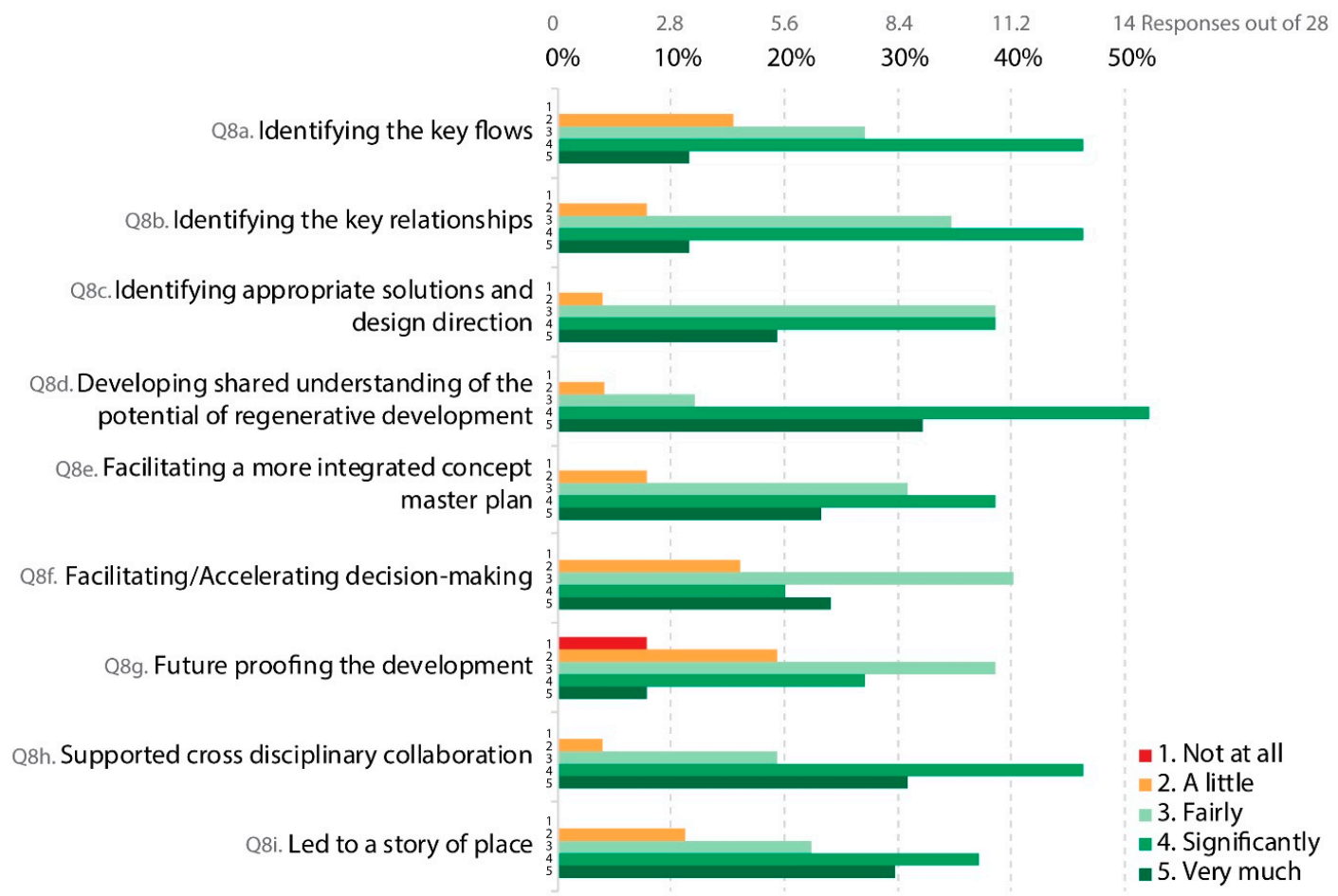

Figure 9. Answers to Question 8 of the online survey on a scale from 1 to 5: "Can you score how well you felt the following parts of the workshop, including the LENSES Framework, worked?".

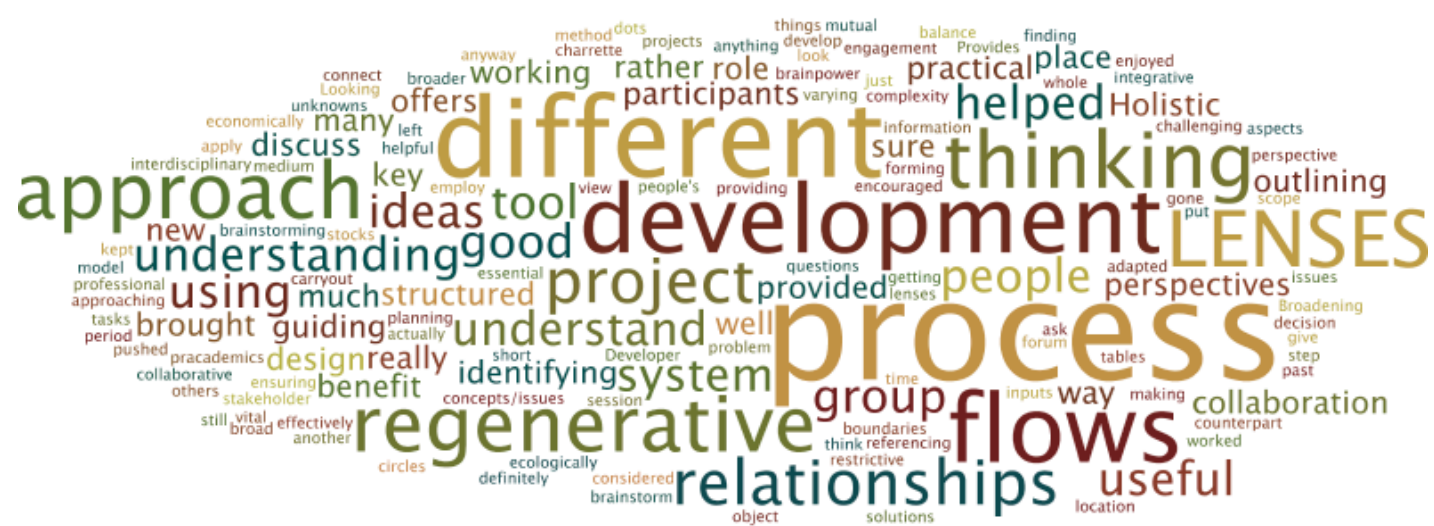

Figure 10. Word cloud summarising the responses of survey participants to Question 9: "What do you feel were the key benefits to using the LENSES process?".

\section{Discussion}

In this section, we discuss (1) the shift in thinking fostered by the process; (2) the project outcomes including the development of the participants; (3) the LENSES Framework; and (4) further research.

\subsection{Shift in Thinking}

Regenerative Development is development that supports the health and vitality of a region through mutually beneficial relationships between all the stakeholders and flows of the system. Through the understanding of the history and potential of the place, and through the understanding of the flows in the LENSES Framework, the Seacombe West project was able to better harness its developmental potential and to consider multiple benefits and flows simultaneously in the concept development stage. As can be seen from the comparison of the two masterplans and the feedback 
from participants, the process and understanding of Regenerative Development have been a driver for the outcome of the masterplan design. In particular, the 2016 masterplanning process benefited from iterative reinforcement of the intention to develop potential, supporting the vitality and viability of the land, and working together across disciplines to increase the depth of understanding of the system.

Comparing the 2003 masterplan to the 2016 masterplan shows how the shift in thinking and masterplanning process contributed to different outcomes, even if this case study should be considered indicative only. For example, the 2016 masterplan shows a greater emphasis on understanding the ecological and social opportunities of the development. Specifically, the integration of systems thinking through the consideration of multiple flows can lead to a development where rich thriving socio-ecological systems emerge and evolve. In other words, the masterplan seems to have shifted from socio-technical thinking (mechanistic worldview) to more socio-ecological thinking (ecological worldview). This is evidenced by incorporating specific locations for ecological typologies: reintroducing freshwater wetlands and freshwater lake, strengthening and valuing salt marshes and the saline aquatic environment. Further evidence includes the integration of specific locations for ecological purposes into the design, such as the 500 ha nature reserve. By looking after the underlying soil, water and nutrient systems, the development can be attuned to nature evolving its own niches. The capacity to co-evolve with nature is also considered through the intention of the development to support research to monitor these systems.

The other key way Regenerative Development approach and the LENSES Framework contributed to the project is enabling the masterplan and the development to adapt via feedback loops as the project evolves. The decisions embedded in the design ideas were made based on the consensus of experts, but it is not until the project is implemented and observed that its performance can be effectively determined. Thus, the design leaves room for iterations and possible future changes to the project, based on the actual outcomes of the first phase to be built. The challenge in this is the ongoing commitment and relationship that the design team and land owners will need to have as the project unfolds, and the willingness to change if design initiatives are not working. This also includes the commitment to invest the time to create an integrated design process and not to move back to disciplinary silos in the detailed design documentation and delivery stages. This is particularly challenging considering that many of the design benefits, particularly ecological outcomes, may take a long time to become evident. Ensuring that there is a core group of people who hold its vision is critical to maintaining a project's intentions over time, as evidenced by similar projects.

Another important discussion for such a long-term project is how financial institutions can support such a process. Within this project, a percentage of the profits of the development was proposed to be reinvested in its ongoing evolution. The other financially relevant strategy was the intention for a percentage of the sale price of each property to contribute towards a community management process for waste, water and energy. How these ideas are implemented in this project is part of the long-term research component. Thus, the challenges and potential of ecological needs, social commitment and financial mechanisms have been considered in terms of how they can enable each other within the whole system.

It is important to clarify that the emergence of these regenerative aspects are correlated with the use of LENSES but direct causation cannot be unequivocally established. Should another facilitation tool be used with the same participants and a talented facilitator, many similar outcomes could emerge. Using a control group might provide some more robust evidence of direct causation between the use of LENSES and the observed outcomes, but replicating the expert knowledge and group composition can be extremely hard to achieve. Further research is needed to establish the effectiveness of LENSES to facilitate regenerative projects (against other tools).

\subsection{Project Outcomes and Participant Development}

The 2016 masterplan shows the interrelated nature of the outcome of the design charrette through the work of different groups and their domain (Built Environment-Housing/building Design/ Site 
Plan; Ecosystems-Analysing/regenerating the natural systems; Land; Water-Design/considerations for regen development; Governance; People; Money; Culture-Thriving live, play, govern; and Inspiration-Thriving economy, culture, music, art, entrepreneurship). Each domain impacted and facilitated the others through continual sharing between the groups via the "pollinators"—individuals from each group who would visit the other groups and ensure that the initiatives were connected and cross-fertilised. Such actions for integration are typical of a regenerative project: it is through the effectiveness, viability and vitality of each of the domains that the whole system thrives as something greater than the sum of its parts. For example, governance affects ecosystems, water and energy, the houses and the ability for the community to thrive. However, this can have negative repercussions. An example can be drawn from the recent experience in Victoria Australia, where a decade-long drought resulted in a policy to stop watering street trees [34]. This led to the reduced vitality and death of these trees, resulting in increased water and energy use in related urban areas due to an increased urban heat island effect [35] and negative impacts on people's health [36,37]. Flow-on effects in a system work both ways.

The results of Workshop 4 and the comparison of the resulting masterplan in 2016 to the original masterplan of 2003 suggest the potential for integration of holistic benefits and creating the potential for increased viability of the area [12,33]. This is highlighted by the stakeholders' comments such as: "[LENSES] really helps us look at not only just the building of the development, but all the other aspects such as the environment and the social outcomes and how the whole development will operate into the future. And so it gives a much deeper and fuller understanding of the project".

In addition, the majority of the participants reported that they felt there was value and benefit from the regenerative process and the LENSES Framework to the project outcomes (see Figure 8), emphasising on how it impacted them and their ability to verbalise what regenerative development is. The participants' own gains were therefore an equally important outcome of this research (see Figure 7). Many participants now carry with them the experience of working towards more holistic outcomes by focusing on the potential of the place rather than solving its problems. For example, "hearing a range of views and opinions and being able to step back and appreciate the project as a whole rather than being focused on only one particular aspect" was highlighted by one of the participants.

The project outcomes and the feedback from the participants support the view that regenerative development was applied and better understood. The uses of LENSES seems to have facilitated this outcome.

\subsection{Performance of the LENSES Framework and Contribution to Future Theory}

The process of Regenerative Development centres on working within a system to enable the potential of the system to emerge and co-evolve, bringing together the participants and facilitating their ability to build on each other's ideas. Continuing from the discussion above, there is evidence that the LENSES Framework facilitated the emergence of such a regenerative approach. This case study revealed a potential beyond that imagined by the clients or designers. In the words of the chief architect: "by providing different contexts to look at different topics in different groups of stakeholders, there were some intermingling of ideas that I wouldn't have necessarily expected to be thought of in those ways". As such, ideas co-evolved towards a vision for a thriving place for all stakeholders of that region. This was facilitated by providing a platform for those in the project to think beyond their disciplinary silos, as was noted by one of the stakeholders in the interviews: "The LENSES process, I believe, is probably quite an interesting way of trying to focus people who have specific expertise [ ... ] onto [common] topics, and [ ... ] breaking down communication barriers [ ... ]". This was also demonstrated in the survey results; referring to question $8 \mathrm{~h}$, no one indicated that the framework "did not" support cross-disciplinary collaboration, while over $75 \%$ of the respondents said that it "significantly" or "very much" supported collaboration.

One of the reasons behind this was the ability to create a shared understanding of the project. This can be seen in question $8 \mathrm{~d}$ where all respondents said that the LENSES Framework contributed to 
a shared understanding with over $80 \%$ stating that this was "significantly" or "very much" the case. This ability to have a common story, a common purpose to a project, has been shown to be critical in the success of complex projects, where the aim is to produce results beyond common practice $[10,38]$. The LENSES Framework supported this by focusing the participants' attention on telling the story through the key principles of the project, and allowing these to interact with the flows and intention to create benefit. This brought intention, creativity, experience and the place together.

The survey results showed that participants wanted more time to understand regenerative development, to understand the LENSES Framework and to resolve and refine ideas and create concrete opportunities. Yet for most projects, the time spent on this activity would not be seen as productive. However, assessing/considering projects across their design, development, construction and handover is critical. The work of Reed and The 7group [39] has shown that integrated project design, where more emphasis is put on the initial holistic concept design that includes all stakeholders, tends to result in projects that are completed faster at a lower cost.

Lastly, it is important to note that the participants scored the LENSES Framework lowest on its ability to future-proof the project. While the participants did not have an opportunity to justify their scores, a speculative reason for this may be a reflection of the project being at such a preliminary stage. It may also be related to the lack of time spent debriefing the project around next steps and how the guidelines would feed into the design, development and construction aspects. Another cause could be what each participant understands by "future proofing" or that this concept was not identified as an intended outcome of the workshop. It is also possible that the LENSES Framework lacks in this particular area.

\subsection{Limitations and Future Research}

As in any research, this study has limitations. The results are valid for the case study project of Seacombe West and may or may not be transferable as they are. The role of the actual workshop facilitator in delivering a regenerative alternative is significant and has not been evaluated in this paper. The bias resulting from the composition of participating stakeholders should also be further evaluated. For example, the strong presence of academics in Workshop 4 might have supported the systematic inclusion of knowledge transfer propositions across all groups. The approach would need to be replicated on a number of projects to identify broader patterns by increasing the overall sample size of projects and of participants evaluated. In addition, the noted differences observed between the 2003 and 2016 masterplans could be due to factors other than the design guidelines proposed at the end of the workshops. The answer of the head architect (who presided the 2016 masterplan to question 6 of the semi-structured interview (Do you think the LENSES process was effective in delivering a project with the potential to create social and ecological benefit, see Appendix B) does supports the effectiveness of LENSES. It reads as follows:

"Sure. Back to the idea about whether lenses is effective or not, I think consciousness about what we're trying to do is a critical element to actually being able to design things that are productive. So to the extent that lenses put upfront and centre the social and ecological attributes that we were trying to achieve, also to a great extent benchmark them against other aspirations, I think that's a very successful way in ensuring that these elements are incorporated into the ultimate design".

However, the composition of the design team, the questions asked and the general design culture at that time could have also led to the differences observed between the 2003 and the 2016 masterplans.

In addition, the implementation of the ideas that were generated during these workshops is actually what matters most. A longitudinal study monitoring the project over time, what ideas were implemented, in what conditions and why, would help shed more light on the long-term benefits of such decision-making process. This constitutes an avenue for future research.

Despite these limitations, this study is one of the first to analyse the process underpinning the emergence of a regenerative design for a large-scale project. The analytical approach used in 
assessing the design process and outcomes provides a methodological contribution for future planning, implementation and assessment of regenerative projects.

\section{Conclusions}

This paper started by posing several questions, reflecting on the design process of Seacombe West project in Victoria, and our research on the effectiveness of using the regenerative development approach using the LENSES Framework to provide more holistic, integrated, living environments.

1. Is the process used in this project justified in terms of investment in time, energy and resources?

It is still too early in the timeline of the project to determine the effectiveness of the process on producing the full development. Given that it is impossible to have a controlled scenario, the justification of its use in the investment of time, energy and resources is more a matter of the stories produced and feedback received overtime than what can be measured. The interviews, survey and outcome of the masterplanning process do support the effectiveness of LENSES. This is most visible in the participants' demand to spend more time on the project.

2. Does the LENSES Framework have the potential to achieve Regenerative Regional Development?

The involvement of a broad range of experts in the workshops has led to a range of ideas that could improve the potential to apply regenerative development in a project, increasing vitality, viability and capacity to evolve. However, the participants also felt that LENSES did not perform as well as in other areas when it came to "future proofing the development". How much the built project will actually achieve regenerative goals will depend on a range of factors, including how many of the ecosystemic ideas are taken on board during implementation.

3. What worked well? What could have been improved?

From the research discussed in this paper it would seem that the LENSES Framework was a useful way to collaborate and to achieve a more interdisciplinary and integrated masterplan. As discussed, other facilitation tools might have led to similar outcomes. From the feedback presented, improvements could be made towards enhancing the users' ability to see the value of the process to envision options for future proofing the outcome. An investigation on how to do so may be warranted.

4. What were the key enablers?

The enablers that allowed this project to apply the regenerative development process and the LENSES Framework were the willingness of the landowners and project participants to participate and to explore the potential of this project together. The willingness of 40 people to give up two days of their normal day-to-day activities to participate in a workshop was also a significant enabler, which was critical to its outcome. Another reflection on a key enabler is the importance of sharing the stories, case studies and experience to support people seeing the potential of a project beyond standard practice.

In conclusion, the process of applying the LENSES Framework in Seacombe West has resulted in a model that is now being applied in three other projects: a Melbourne University precinct; a surfing community water treatment plant in New Zealand; and a two-year research and education program on place-making, including 20 redesigned places around Australia. All these projects are capitalising on lessons learned in applying LENSES in the Seacombe West project, namely understanding regenerative development and creating the various lenses in consultation with key stakeholders. This is a tribute to this research which aimed at understanding the process behind the emergence of regenerative development in order to better apply it.

Acknowledgments: The authors would like to thank Michelle Fisher and Lewis Lo for their help in editing this paper. This project has been supported by the University of Melbourne's Carlton Connect Initiatives Fund (CCIF). 
This program seeks to support interdisciplinary, externally-engaged research impact. It was also supported by the land owners James and Harry Troedel and the design and research teams. The authors would also like to thank all participants across all workshops as well as Professor Brian Dunbar from Colorado State University, USA, for his valuable assistance in facilitating the workshops. Finally, the authors are indebted to the anonymous reviewers for their valuable feedback, notably in improving the discussion and nuancing the results.

Author Contributions: Dominique Hes and André Stephan conceived and designed the workshops; Dominique Hes and André Stephan conducted the workshops; André Stephan, Sareh Moosavi and Dominique Hes analysed the data; André Stephan, Dominique Hes and Sareh Moosavi wrote the paper.

Conflicts of Interest: The authors declare no conflict of interest.

\section{Appendix A. Survey Questionnaire}

This appendix presents the questions of the online survey. A description of the three Likert-scales used is provided in Table A1.

Table A1. Likert scales used in the online survey.

\begin{tabular}{lll}
\hline Likert Scale 5 & Likert Scale 7a & Likert Scale $7 \mathbf{b}$ \\
\hline Not at all & Waste of time & Totally confused \\
A little & None & A little confused \\
Fairly & A little & Barely \\
Significantly & Some interest & A little \\
Very much & Useful & Enough \\
& Essential & A lot \\
& This changes everything & Everything I need to know \\
\hline
\end{tabular}

The questions are given below in bold and the answer format between hyphens afterwards.

1. What is your role? (select from: Architect, Engineer, Scientist, Community Member, Indigenous Representative, Government Member, Other (specify)

2. Which workshops did you participate in? (select one or more from workshops 2-4)

3. How much value do you feel YOU gained personally from attending this/these workshop(s)? (Likert Scale 7a)

4. What did you gain from attending? (Free answer)

5. How much value do you feel the PROJECT gained from this/these workshop(s)? (Likert Scale 7a)

6. How well do you think you understand regenerative development? (Likert Scale 7b)

7. In your own words what do you think regenerative development is? (Free answer)

8. On a scale from 1 to 5 , can you score how well you felt the following parts of the workshop, including the LENSES Framework worked? (Likert Scale 5)
a. Identifying the key flows
b. Identifying the key relationships
c. Identifying appropriate solutions and design directions
d. Developing shared understanding of the potential of regenerative development
e. Facilitating a more integrated concept masterplan
f. Facilitating/Accelerating decision-making
g. Future proofing the development
h. Supported cross disciplinary collaboration
i. Led to a story of place

9. What do you feel were the key benefits to using the LENSES process? (Free answer)

10. What do you feel were the key areas for improvement in using the workshop, including the LENSES Process? (Free answer) 


\section{Appendix B. Semi-Structured Interview Questions}

The questions used in the semi-structured interviews are listed below, by order:

1. In your own words how would you describe regenerative development?-if not mentioned prompts around social and ecological aspects

2. Which workshops did you participate in?

3. What is your interest in participating in the workshops?

4. What aspects that came out of the workshop do you think were surprising?

5. How would you describe the LENSES process in comparison to a traditional workshop approach?

6. Do you think the LENSES process was effective in delivering a project with the potential to create social and ecological benefit?

7. What were the things you think worked really well in the workshops?

8. What things do you feel could have used improvement?

\section{References}

1. Lyle, J.T. Regenerative Design for Sustainable Development; John Wiley: New York, NY, USA, 1994; p. xiv, 338p.

2. McDonough, W.; Braungart, M. Cradle to Cradle : Remaking the Way We Make Things, 1st ed.; North Point Press: New York, NY, USA, 2002; p. 193.

3. Birkeland, J. Positive Development: From Vicious Circles to Virtuous Cycles through Built Environment Design; Earthscan: London, UK; Sterling, VA, USA, 2008; p. xxii, 408p.

4. Cole, R.J. Transitioning from green to regenerative design. Build. Res. Inf. 2012, 40, 39-53. [CrossRef]

5. Mang, P.; Reed, B. Designing from place: A regenerative framework and methodology. Build. Res. Inf. 2012, 40, 23-38. [CrossRef]

6. Du Plessis, C. Shifting Paradigms to Study Urban Sustainability; World Sustainable Building Conference (WSB11): Helsinki, Finland, 2011; pp. 4-17.

7. Du Plessis, C. Using the long lever of value change. In Motivating Change: Sustainable Design and Behaviour in the Built Environment; Crocker, R., Lehmann, S., Eds.; Routledge: London, UK, 2013; pp. 92-108.

8. Cole, R.J. Regenerative design and development: Current theory and practice. Build. Res. Inf. 2012, 40, 1-6. [CrossRef]

9. Du Plessis, C. Towards a regenerative paradigm for the built environment. Build. Res. Inf. 2012, 40, 7-22. [CrossRef]

10. Hes, D.; du Plessis, C. Designing for Hope: Pathways to Regenerative Sustainability; Routledge: London, UK, 2015; p. 248.

11. Robinson, J.; Cole, R.J. Theoretical underpinnings of regenerative sustainability. Build. Res. Inf. 2014, 43, 133-143. [CrossRef]

12. Plaut, J.M.; Dunbar, B.; Gotthelf, H.; Hes, D. Regenerative Development through Lenses: Building Health and Vitality in Natural, Social, and Economic Systems. Available online: http:/ / www.clearabundance.org/wpcontent/uploads/2017/10/EDG-Aus.-Inst.-of-Arch-Final-compressed.pdf (accessed on 8 February 2018).

13. Benyus, J.M. Biomimicry: Innovation Inspired by Nature, 1st ed.; Morrow: New York, NY, USA, 1997; p. 308.

14. Roberts, A.M.; Pannell, D.J.; Doole, G.; Vigiak, O. Agricultural land management strategies to reduce phosphorus loads in the gippsland lakes, australia. Agric. Syst. 2012, 106, 11-22. [CrossRef]

15. Ramsar. The Ramsar Convention and Its Mission. Available online: http://ramweb-uat.neox24.ch/about/ the-ramsar-convention-and-its-mission (accessed on 13 June 2017).

16. Department of the Environment and Energy. Criteria for Identifying Wetlands of International Importance. Available online: http://www.environment.gov.au/water/wetlands/ramsar/criteria-identifying-wetlands (accessed on 12 April 2017).

17. Parks Victoria. Lake Wellington Wetlands Management Plan; Parks Victoria: Melbourne, Australia, 2008; p. 70.

18. Boon, P.I.; Cook, P.; Woodland, R. The gippsland lakes: Management challenges posed by long-term environmental change. Mar. Freshw. Res. 2016, 67, 721-737. [CrossRef] 
19. Webster, I.; Parslow, J.; Grayson, R.; Molloy, R.; Andrewartha, J.; Sakov, P.; Tan, K.S.; Walker, S.; Wallace, B. Gippsland Lakes Environmental Study: Assessing Options for Improving Water Quality and Ecological Function; Gippsland Coastal Board: Melbourne, Australia, 2001.

20. Love Our Lakes. Living Here: Keep Our Lakes Healthy and Think about Where Your Stormwater Goes. Available online: http:/ / www.loveourlakes.net.au/living-here/ (accessed on 14 June 2017).

21. Oxford Dictionaries. Viability. Available online: https://en.oxforddictionaries.com/definition/viability (accessed on 27 April 2017).

22. Jahn, T.; Bergmann, M.; Keil, F. Transdisciplinarity: Between mainstreaming and marginalization. Ecol. Econ. 2012, 79, 1-10. [CrossRef]

23. Hoffmann, S.; Pohl, C.; Hering, J.G. Exploring transdisciplinary integration within a large research program: Empirical lessons from four thematic synthesis processes. Res. Policy 2017, 46, 678-692. [CrossRef]

24. Klein, J.T. Research integration: A comparative knowledge base. In Case Studies in Interdisciplinary Research; Repko, A., Newell, W., Szostak, R., Eds.; SAGE Publications, Inc.: Thousand Oaks, CA, USA, 2012; pp. 283-298.

25. Plaut, J.M.; Dunbar, B.; Wackerman, A.; Hodgin, S. Regenerative design: The lenses framework for buildings and communities. Build. Res. Inf. 2012, 40, 112-122. [CrossRef]

26. Goldsmith, E. The Way: An Ecological World-View, 1st Shambhala ed.; Random House: Boston, NY, USA, 1993; p. xxii. 442 p.

27. Rees, W.E. Achieving sustainability: Reform or transformation? In The Earthscan Reader in Sustainable Cities; Satterthwaite, D., Ed.; Earthscan: London, UK, 1999.

28. Capra, F. The Hidden Connections: Integrating the Biological, Cognitive, and Social Dimensions of Life into a Science of Sustainability, 1st ed.; Doubleday: New York, NY, USA, 2002; p. xix, 300p.

29. Sterling, S. Whole Systems Thinking as a Basis for Paradigm Change in Education: Explorations in the Context of Sustainability. Ph.D Thesis, University of Bath, Bath, UK, 2003.

30. Bourne, E.J. Global Shift: How a New Worldview Is Transforming Humanity; Noetic Books; New Harbinger Publications: Petaluma, CA, USA; Oakland, CA, USA, 2008; p. viii, 337p.

31. Nulty, D.D. The adequacy of response rates to online and paper surveys: What can be done? Assess. Eval. High. Educ. 2008, 33, 301-314. [CrossRef]

32. Baruch, Y.; Holtom, B.C. Survey response rate levels and trends in organizational research. Hum. Relat. 2008, 61, 1139-1160. [CrossRef]

33. Hes, D.; Stephan, A.; Moosavi, S. Net regenerative regional development: Implementation in the masterplanning stage of a 680 hectares case study. In Fifty Years Later: Revisiting the Role of Architectural Science in Design and Practice: 50th International Conference of the Architectural Science Association; Zuo, J., Daniel, L., Soebarto, V., Eds.; The Architectural Science Association and The University of Adelaide: Adelaide, Australia, 2016; pp. 845-854.

34. May, P.B.; Livesely, S.J.; Shears, I. Managing and monitoring tree health and soil water status during extreme drought in melbourne, victoria. Arboric. Urban For. 2013, 39, 10.

35. Livesly, S.; Caffin, M.; Dawkins, A.; Lu, A.; Hes, D. Effect of vegetation around buildings on space conditioning energy and water consumption. In Sustainable Buildings-B11; Hong Kong Green Building Council (HKGBC): Helsinki, Finland, 2011.

36. Chen, D.; Wang, X.; Thatcher, M.; Barnett, G.; Kachenko, A.; Prince, R. Urban vegetation for reducing heat related mortality. Environ. Pollut. 2014, 192, 275-284. [CrossRef] [PubMed]

37. VAGO. Heatwave Management: Reducing the Risk to Public Health; Victorian Auditor-General's Office: Melbourne, Australia, 2014; p. 74.

38. Mang, P.; Haggard, B. Regenerative Development and Design: A Framework for Evolving Sustainability; John Wiley \& Sons, Inc.: Hoboken, NJ, USA, 2016.

39. Reed, B.; The 7 group. The Integrative Design Guide to Green Building: Redefining the Practice of Sustainability; Wiley: Hoboken, NJ, USA, 2009; p. xiv, 398p.

(C) 2018 by the authors. Licensee MDPI, Basel, Switzerland. This article is an open access article distributed under the terms and conditions of the Creative Commons Attribution (CC BY) license (http:// creativecommons.org/licenses/by/4.0/). 